\title{
Design of Tailored Gamified Educational Systems Based on Gamer Types
}

\author{
Wilk Oliveira dos Santos ${ }^{1}$, Ig Ibert Bittencourt (advisor) ${ }^{1}$, Julita Vassileva (co-advisor) ${ }^{2}$ \\ ${ }^{1}$ Center of Excellence for Social Technologies (NEES) - Computer Institute (IC) - Federal \\ University of Alagoas (UFAL) - Maceió, AL - Brazil \\ ${ }^{2}$ Department of Computer Science - University of Saskatchewan \\ Saskatoon, SK - Canada. \\ \{wos,ig.ibert\}@ic.ufal.br, jiv@cs.usask.ca
}

\begin{abstract}
One of the main contemporary challenges in the field of computers and education is to provide gamified educational systems tailored according to the students' gamer types to be most effective than traditional counter-tailored gamified educational systems in terms of students' learning aspects. In order to start to solve this problem, we proposed an approach to tailor gamified educational systems based on the students' gamer types. An instance of the proposed approach was implemented and an empirical experiment with 121 elementary students was conducted in order to comparatively evaluate the tailored and the counter-tailored versions of the system in terms of students' concentration and flow experience. The main results indicate that for some gamer types the tailored system was more effective, however, in some cases, the flow experience and concentration was larger in the counter-tailored version of the system, surprising and contradicting the expectation of recent theoretical studies and making room for further studies in this field. A second empirical experiment was conducted in order to identify which are the most suitable gamification element for each gamer type, allowing us to provide a guideline for tailor gamified educational systems based on students' gamer types.
\end{abstract}

\section{Introduction}

To target the problem of students' evasion, disengagement, and demotivation in educational systems, recent researchers have used games and gamification elements along with their activities "Monterrat et al. 2014a, Challco et al. 2015a, Battistella and von Wangenheim 2016]. Their aim is to decrease students' evasion, frustration, and demotivation as well as to improve student's concentration, engagement, and learning aspects in the educational systems [Paiva et al. 2015b, Cózar-Gutiérrez and Sáez-López 2016, Paiva et al. 2016]. These studies are implementing and evaluating the use of gamification techniques in educational systems, raising the concept of gamified educational systems.

Recent results have shown that these systems can offer different ways for the students to perform the educational activities associated with gamification elements [Hamari et al. 2014, Nah et al. 2014, Dicheva and Dichev 2015]. In addition, gamified 
VII Congresso Brasileiro de Informática na Educação (CBIE 2018)

Anais dos Workshops do VII Congresso Brasileiro de Informática na Educação (WCBIE 2018)

educational systems may provide a number of benefits to students, for instance, increasing students' motivation [Hanus and Fox 2015, Cózar-Gutiérrez and Sáez-López 2016], and students' learning performance [Nah et al. 2014, Pedro et al. 2015].

However, other studies are showing that, at several cases, the use of gamification in an educational context (especially gamified educational systems) does not necessarily improve the students' motivation, engagement, and learning [Hamari et al. 2014, Orji 2014, Orji et al. 2014]. These results are bringing the attention of the community for the need of deeper studies to identify when and how the use of gamification is really effective to improve the students' satisfaction and to propose solutions to provide, indeed, a better gamification design which might impact on learning performance [Hamari et al. 2014, Hamari et al. 2016].

In gamified educational systems, it is of utmost importance to consider that students have different gamer types. Thus, they might be more or less motivated in different ways, according to their gamer types [Orji et al. 2014, Monterrat et al. 2014c, Masthoff and Vassileva 2015]. As such, depending on the approach used in these systems, the impact of gamification may be harmful to the students' motivation, engagement, flow experience and so on. So, actually, provide adapted gamified educational systems according to the students' gamer type is one of the most important challenges in the field of computers and educations [Orji 2014, Monterrat et al. 2014c, Masthoff and Vassileva 2015].

Based on the recent challenges of providing adapted educational systems for each student and the hypothesis that the students have different perceptions according to their gamer type, this master proposed an approach to tailor gamified educational systems according to the students' gamer types. We tailored a real gamified intelligent educational system based on the proposed approach. We also conducted an experiment in order to evaluate the system tailored based on our approach with 121 elementary students in terms of students' concentration and flow experience [Csikszentmihalyi 1997], comparing the tailored and counter-tailored version of the systems.

The main results indicate that the tailored system was more effective in terms of students' concentration and flow experience, however, in some cases the flow experience and concentration was larger in the counter-tailored version of the system, contradicting the expectations of important recent theoretical studies. In addition, we conducted a second experiment to identify the most suitable gamification elements for each gamer type, providing a guideline with the most suitable gamification elements for each. We also classified the preferences of the gamification elements according to the students' gender.

\section{Background}

This section presents the main topic addressed in this study. We will also to present our main related works.

\subsection{Tailored Gamification}

In order to solve some problems related to the use of gamification in educational systems, in the last years, many studies have been highlighted the challenge of tailor the gamification according to the students' individual characteristics [Orji et al. 2013, Monterrat et al. 2014b, Monterrat et al. 2015]. These are in general proposing a different solution to tailor gamified educational systems and investigating the importance of 
VII Congresso Brasileiro de Informática na Educação (CBIE 2018)

Anais dos Workshops do VII Congresso Brasileiro de Informática na Educação (WCBIE 2018)

personalizing gamified educational systems based on students' characteristics. Based on that, in summary, the idea of tailored gamification is to provide an adapted gamification design in the systems based on the different users' needs and preferences.

\subsection{Related Works}

In order to provide an effective solution, we conducted a Systematic Literature Review (SLR) in order to identify a state of the art on tailored gamification for educational technologies and found our related works. We identified 18 related works and compared these studies with our study in eight different criteria: $(i)$ the study was conducted in the field of gamified educational systems; (ii) the study was developed based on an empirical methodology; (iii) the study provides details about the implementation; (iv) the study provides details about the evaluation; (v) the study provides an empirical evaluation; (vi) the study provides an evaluation of the industrial and academical context; (vii) the study used a modern player model, (e.g., HEXAD [Marczewski 2013] or BrainHex [Nah et al. 2014]); (viii) the study presents a comprehensive discussion of its results. A list of our main related works can be found at the following link: https://goo.gl/PY9AWP.

Based on the analysis of our related works, it is possible to perceive that most of the studies do not provide some important criteria, such as details about its implementation or empirical validation of the proposal. Complete studies from the terms addressed in this analysis (e.g., [Orji et al. 2013, Orji et al. 2014, Challco et al. 2015b]), were conducted in the health science field. The comparison also shows that the studies conducted in the field of gamified educational system (e.g., [Monterrat et al. 2014a, Monterrat et al. 2014c]) are initial studies, generally not providing an empirical evaluation or considering modern player models. The comparison indicated that our proposal is the only one to present all the evaluated items. Our study is also the only one to evaluate the tailored gamified educational system in terms of students' flow experience.

\section{Proposal}

The proposal of this study consists of an approach to tailor gamified educational systems, taking into account the seven different BrainHex gamer types (Seeker, Survivor, Daredevil, Mastermind, Conqueror, Achiever, and Socializer) [Nacke et al. 2014]. The proposal was developed based on Orji's guidelines [Orji et al. 2013] that define which are the best persuasive technologies strategies (PT strategies) to each gamer type. The Figure 1 presents a general view of the proposed approach. Following, we also present details about each step of our proposal.

1. User's identification: in the first moment, the approach provides options for the students to create an account in the system and provide basic information, such as login, password, email, and others (according to the default system specifications);

2. Gamer type identification: the gamer type identification consists of a semiautomatic process, based on the BrainHex player model. At this moment, the approach provides the BrainHex questionnaire to the students. After the student completes the questionnaire, the system should process the student' answers, identify the student' gamer type, sending this information for the Tailoring Model;

3. Tailoring model: the tailoring model is the main step of the approach. The tailoring model is responsible for associate the most suitable game design elements to each student' gamer type; 


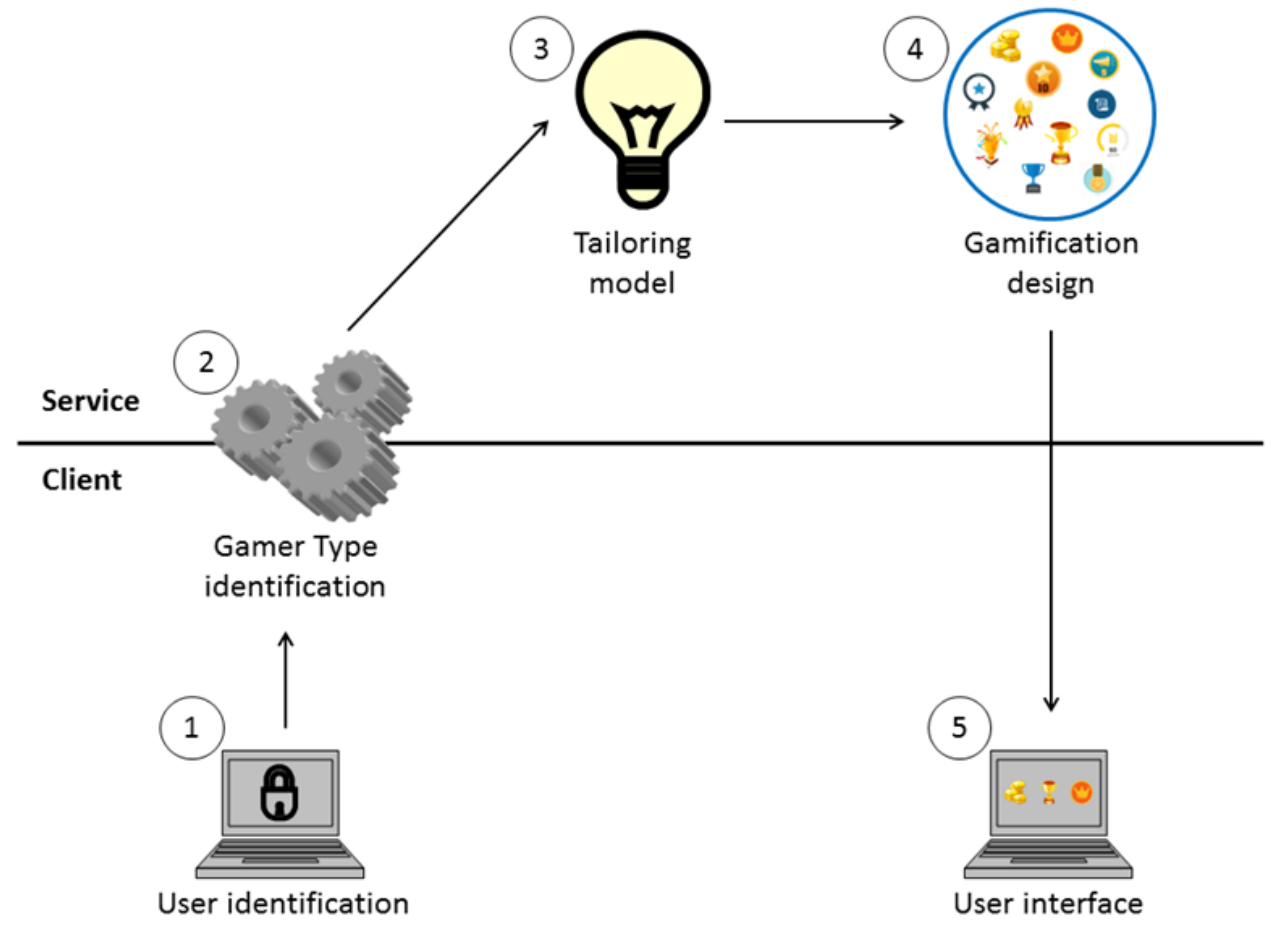

Figure 1. Proposed Approach

4. Gamification design: the gamification design is the system model, responsible for generating the students' graphical interface with the most suitable game design elements associated with their gamer type;

5. User's interface: the user interface represents the system output and is responsible for providing the gamification elements design associated with their player type, generated by the gamification design model.

This is a general approach, independent of the pedagogical aspects of the system. The approach can be plugged into different types of educational system and implemented, independent of technical system requirements and pedagogical design. For instance, our approach can be implemented in a gamified educational system for teaching math or in an educational gamified app to teach a language.

\subsection{Proposal Implementation}

In order to avoid validity threats related to the implementation design, we chose to implement an instance of our approach from an already existing system and empirically validated. For that, we used the gamified educational system MeuTutor [Paiva et al. 2015a]. The system was chosen after a comparative analysis between nine different gamified intelligent educational system. MeuTutor was of interest for this study because it was considered more geographically accessible, as well as implementing the nine most used gamification elements in a gamified intelligent educational system, as identified by [Nah et al. 2014]. 
VII Congresso Brasileiro de Informática na Educação (CBIE 2018)

Anais dos Workshops do VII Congresso Brasileiro de Informática na Educação (WCBIE 2018)

\section{Experiments}

In order to validate our proposal, an empirical experiment was conducted based on the GQM process [Caldiera and Rombach 1994]. We compared the tailored with the counter-tailored version of the system for each gamer type in terms of students' concentration and flow experience [Csikszentmihalyi 1997]. First, we identified the students' gamer type through the BrainHex player model (plugged in the system through the proposed approach) and the students' concentration and flow experience during their use of the system through a validate Flow State Scale (FSS) for the field of gamification [Hamari and Koivisto 2014]. To analyze the data, initially, we applied four different statistical tests commonly used in the community to calculate the normality of data (ShapiroWilk, Kolmogorov-Smirnov, Skewness and Kurtosis) and analyzed Boxplots, Histograms and QQ plots to support our decision about the data normality [Wohlin et al. 2012]. Then, we applied statistical tests to verify our hypothesis regarding the students' perception (one-way analysis of variation (ANOVA) and Tukey's test), based on the Wohlin's recommendations [Wohlin et al. 2012].

We also conducted a second experiment in order to identify the most suitable gamification elements for each BrainHex gamer type. After identifying the students' gamer type (through the BrainHex player model) we applied a survey asking the students to answer about their level of preference for each gamification element, considering the eight game design elements that are used extensively in the educational and learning contexts (Points, Levels/Stages, Badges, Leaderboards, Prizes and Rewards, Progress bars, Storyline, and Feedback) [Nah et al. 2014], in a 7-point Likert-Scale [Likert 1932]. To verify the research hypothesis, we first performed a descriptive analysis of the data and then we applied statistical tests (the same test applied in the first experiment). This project and experiment was approved by the Canadian Behavioural Research Ethics Committee with the code BEH\#16-142.

\section{Results}

The results of the first experiment allowed us to confirm that the tailored system was most effective for some gamer types (i.e., Daredevil and Seeker), but, for other gamer types (i.e., Mastermind and Survivor) the counter-tailored system was most effective, contradicting the expectations of recent studies [Orji et al. 2013, Orji 2014, Monterrat et al. 2015], and, highlighting the importance of conducting deeper empirical studies in this field. The Figure 2 shows the comparison between students' flow experience in the tailored and in the counter-tailored system. The blue line represents the students' flow experience in the tailored system and the red line represents the flow experience in the counter-tailored version.

The results of the second experiment confirm that the different gamer types have also different preferences about the gamification elements. We identified internal statistical differences about the gamification elements for each gamer type. The results also allowed us to identify the most suitable gamification elements for each gamer type and provide a guideline to tailor gamified educational systems based on students' gamer types, recommending which are the most suitable gamification elements for each gamer type. The Table 1 summarizes the statistical analysis, and the Table 2 presents the guideline with the most suitable gamification element for each gamer type. 
VII Congresso Brasileiro de Informática na Educação (CBIE 2018)

Anais dos Workshops do VII Congresso Brasileiro de Informática na Educação (WCBIE 2018)

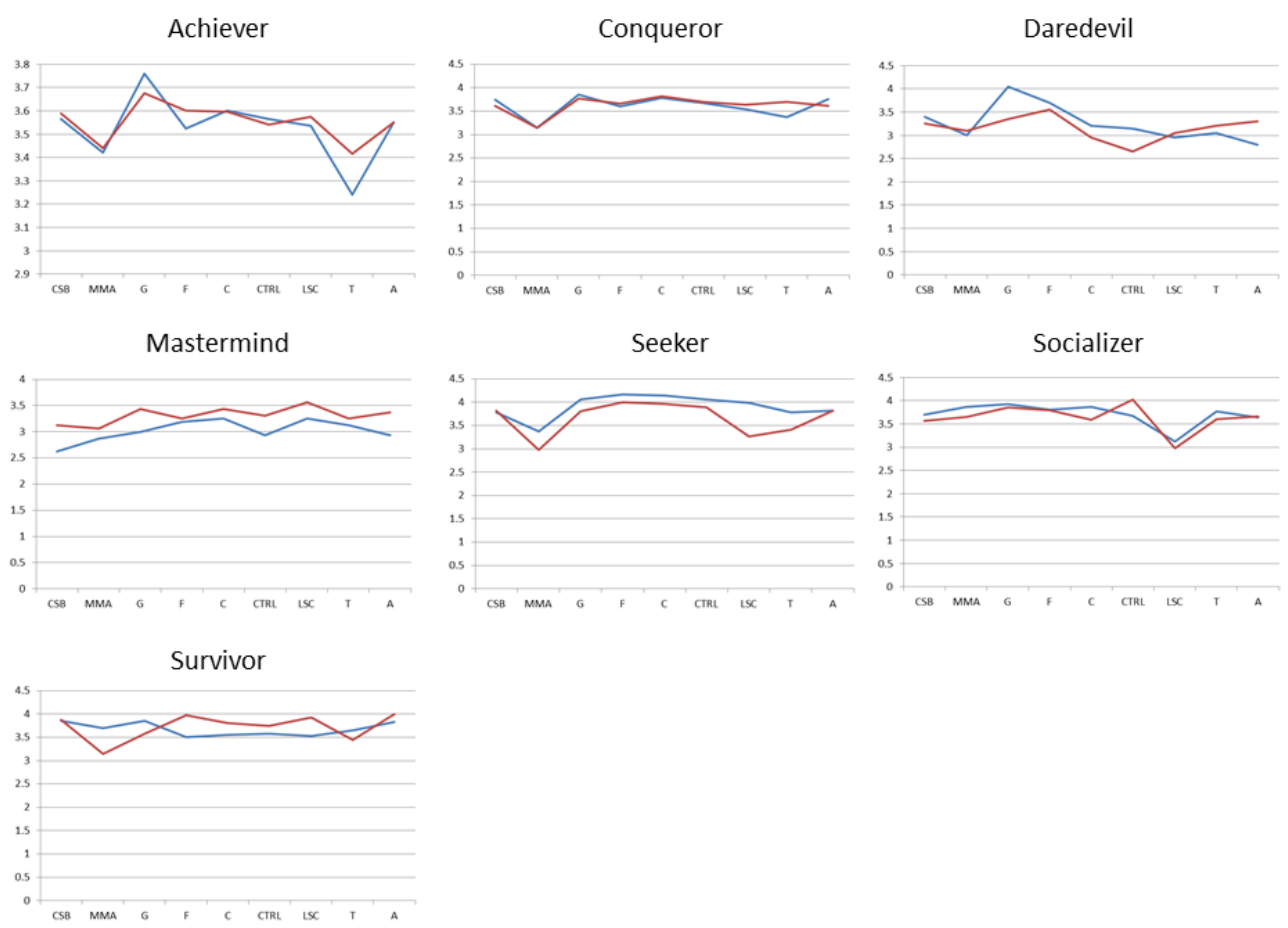

Figure 2. Students' Flow Experience

Table 1: Students' gamification elements preferences

\begin{tabular}{lccccc}
\hline Gamification elements & Mean & Median & Mod & $\operatorname{var}(X)$ & SD \\
\hline \multicolumn{5}{c}{ Achiever } \\
\hline Points & 5.23 & 7 & 5 & 3.54 & 1.88 \\
Badges & 5.27 & 7 & 6 & 3.35 & 1.83 \\
Trophies & 5.31 & 7 & 6 & 3.28 & 1.81 \\
Levels & 4.94 & 7 & 5 & 3.29 & 1.81 \\
Progress bar & 5.38 & 7 & 6 & 2.54 & 1.59 \\
Ranking & 5.21 & 7 & 6 & 4.47 & 2.11 \\
Timeline & 4.04 & 5 & 4 & 3.96 & 1.99 \\
History & 5.23 & 7 & 5 & 3.29 & 1.81 \\
Avatars & 5.31 & 7 & 6 & 4.35 & 2.08 \\
Feedback & 4.48 & 7 & 5 & 4.30 & 2.07 \\
\hline \multicolumn{5}{c}{ Conqueror } \\
Points & 5.21 & 7 & 5 & 2.69 & 1.64 \\
Badges & 5.75 & 7 & 7 & 2.86 & 1.69 \\
Trophies & 5.25 & 7 & 6 & 3.23 & 1.80 \\
Levels & 5.57 & 7 & 6 & 2.33 & 1.53 \\
Progress bar & 5.54 & 7 & 6 & 3.22 & 1.79 \\
Ranking & 5.5 & 7 & 6 & 3.00 & 1.73 \\
Timeline & 4.21 & 4 & 4 & 3.51 & 1.87 \\
History & 5.07 & 7 & 5.5 & 3.62 & 1.90 \\
\hline
\end{tabular}


VII Congresso Brasileiro de Informática na Educação (CBIE 2018)

Anais dos Workshops do VII Congresso Brasileiro de Informática na Educação (WCBIE 2018)

\begin{tabular}{|c|c|c|c|c|c|}
\hline Avatars & 5.36 & 7 & 6 & 3.87 & 1.97 \\
\hline Feedback & 4.75 & 7 & 5 & 4.12 & 2.03 \\
\hline \multicolumn{6}{|c|}{ Daredevil } \\
\hline Points & 4.17 & 4.00 & 4.00 & 3.37 & 1.83 \\
\hline Badges & 4.50 & 5.00 & 4.50 & 2.70 & 1.64 \\
\hline Trophies & 4.67 & 7.00 & 5.00 & 6.67 & 2.58 \\
\hline Levels & 5.50 & 7.00 & 6.00 & 3.90 & 1.97 \\
\hline Progress bar & 3.67 & 3.00 & 3.50 & 3.87 & 1.97 \\
\hline Ranking & 4.50 & 4.00 & 4.50 & 4.30 & 2.07 \\
\hline Timeline & 3.83 & 4.00 & 4.00 & 4.57 & 2.14 \\
\hline History & 3.83 & 5.00 & 4.50 & 2.57 & 1.60 \\
\hline Avatars & 4.67 & 6.00 & 5.50 & 3.87 & 1.97 \\
\hline Feedback & 4.00 & 5.00 & 4.50 & 1.60 & 1.26 \\
\hline \multicolumn{6}{|c|}{ Seeker } \\
\hline Points & 5.13 & 7.00 & 5.00 & 4.38 & 2.09 \\
\hline Badges & 5.50 & 7.00 & 6.00 & 4.00 & 2.00 \\
\hline Trophies & 5.13 & 7.00 & 5.00 & 3.32 & 1.82 \\
\hline Levels & 4.81 & 6.00 & 5.00 & 3.50 & 1.87 \\
\hline Progress bar & 4.94 & 5.00 & 5.00 & 3.13 & 1.77 \\
\hline Ranking & 4.69 & 6.00 & 5.50 & 5.30 & 2.30 \\
\hline Timeline & 4.19 & 7.00 & 4.50 & 6.16 & 2.48 \\
\hline History & 4.94 & 7.00 & 4.50 & 3.26 & 1.81 \\
\hline Avatars & 5.63 & 7.00 & 6.00 & 1.85 & 1.36 \\
\hline Feedback & 4.81 & 7.00 & 5.00 & 3.90 & 1.97 \\
\hline \multicolumn{6}{|c|}{ Socializer } \\
\hline Points & 4.67 & 4.00 & 4.00 & 2.50 & 1.58 \\
\hline Badges & 5.33 & 6.00 & 6.00 & 2.00 & 1.41 \\
\hline Trophies & 4.33 & 4.00 & 4.00 & 3.75 & 1.94 \\
\hline Levels & 5.22 & 7.00 & 6.00 & 3.69 & 1.92 \\
\hline Progress bar & 4.78 & 6.00 & 6.00 & 4.19 & 2.05 \\
\hline Ranking & 5.67 & 7.00 & 7.00 & 2.50 & 1.58 \\
\hline Timeline & 4.56 & 3.00 & 4.00 & 3.28 & 1.81 \\
\hline History & 4.78 & 6.00 & 5.00 & 1.94 & 1.39 \\
\hline Avatars & 5.56 & 7.00 & 6.00 & 2.28 & 1.51 \\
\hline Feedback & 4.89 & 7.00 & 5.00 & 4.36 & 2.09 \\
\hline \multicolumn{6}{|c|}{ Survivor } \\
\hline Points & 5.17 & 5.00 & 5.00 & 2.88 & 1.70 \\
\hline Badges & 6.08 & 7.00 & 7.00 & 1.54 & 1.24 \\
\hline Trophies & 5.50 & 7.00 & 6.00 & 3.36 & 1.83 \\
\hline Levels & 5.58 & 7.00 & 6.00 & 1.90 & 1.38 \\
\hline Progress bar & 5.58 & 7.00 & 6.00 & 2.45 & 1.56 \\
\hline Ranking & 5.83 & 7.00 & 7.00 & 3.79 & 1.95 \\
\hline Timeline & 5.17 & 7.00 & 5.50 & 3.24 & 1.80 \\
\hline History & 5.58 & 7.00 & 7.00 & 3.54 & 1.88 \\
\hline Avatars & 6.50 & 7.00 & 7.00 & 1.00 & 1.00 \\
\hline
\end{tabular}


VII Congresso Brasileiro de Informática na Educação (CBIE 2018)

Anais dos Workshops do VII Congresso Brasileiro de Informática na Educação (WCBIE 2018)

\begin{tabular}{|c|c|c|c|}
\hline Feedback & 4.67 & 5.00 & 5.00 \\
\hline
\end{tabular}

Table 2. Most suitable gamification element for each gamer type

\begin{tabular}{lllllll}
\hline Gamer Type & \multicolumn{5}{c}{ Gamification elements } \\
\hline Achiever & Points & Progress bar & Trophies & Avatars & Badges & \\
Conqueror & Points & Badges & Levels & Progress bar & Ranking & Avatars \\
Daredevil & Levels & Trophies & Avatars & Badges & Ranking & \\
Seeker & Avatars & Badges & Trophies & Points & & \\
Socializer & Points & Ranking & Avatars & Badges & Levels & \\
Survivor & Avatars & Badges & Ranking & & & \\
\hline
\end{tabular}

\section{Main Contributions}

The main contributions of this master thesis are found in the field of computers and education, and game studies. In order to organize our main contributions, we will summarize the contributions next: (i) A Systematic Literature Review about Flow Theory applied to Computers and Education; (ii) a Systematic Literature Review about personalized gamification in the field Computers and Education; (iii) a Brazilian version of BrainHex player model; (iv) an computational approach to tailor gamified intelligent educational systems based on gamer types; $(v)$ a tailored gamified intelligent educational systems; $(v i)$ two empirical experiments, one in order to validate our proposal and other in order to identify the most suitable gamification elements for each BrainHex gamer type; (vii) a guideline to tailor gamified intelligent educational systems and the most suitable gamification elements for each gamer type; and (viii) a guideline with the most suitable gamification elements for males and females. Our contributions generated a series of publications such as books and articles, as well as a series of software registered at the Brazilian National Institute of Industrial Property. Due to the reduced space of the paper, we chose to present in the following link, an external file with details regarding each contribution (indicating its respective section in the master's thesis) as well as a list of publications, registered software, and awards: https://goo.gl/YYQyVn.

\section{Concluding Remarks}

This study proposed a computational approach to tailor gamified educational systems based on students' gamer types. An instance of the approach was empirically evaluated. We provided a series of contributions related to our proposal, including a guideline to tailor gamified educational systems based on students' gamer types, a guideline with the most suitable gamification elements for each gamer type and two different systematic literature reviews. As future works, we hope to deepen the research on the neurobiological implications of gamer identities in the learning process and propose a model for the realtime identification of students' gamer types in gamified educational systems, as well as to propose a model for the automatic and real-time adaptation of intelligent gamified educational systems based on students' gamer type. 
VII Congresso Brasileiro de Informática na Educação (CBIE 2018)

Anais dos Workshops do VII Congresso Brasileiro de Informática na Educação (WCBIE 2018)

\section{References}

[Battistella and von Wangenheim 2016] Battistella, P. E. and von Wangenheim, C. G. (2016). Engaged: A game development process for teaching computing. In Brazilian Symposium on Computers in Education, volume 27, page 380.

[Caldiera and Rombach 1994] Caldiera, V. R. B.-G. and Rombach, H. D. (1994). Goal question metric paradigm. Encyclopedia of Software Engineering, 1:528-532.

[Challco et al. 2015a] Challco, G. C., Mizoguchi, R., Bittencourt, I. I., and Isotani, S. (2015a). Gamification of collaborative learning scenarios: Structuring persuasive strategies using game elements and ontologies. In International Workshop on Social Computing in Digital Education, pages 12-28. Springer.

[Challco et al. 2015b] Challco, G. C., Moreira, D. A., Bittencourt, I. I., Mizoguchi, R., and Isotani, S. (2015b). Personalization of gamification in collaborative learning contexts using ontologies. IEEE Latin America Transactions, 13(6):1995-2002.

[Cózar-Gutiérrez and Sáez-López 2016] Cózar-Gutiérrez, R. and Sáez-López, J. M. (2016). Game-based learning and gamification in initial teacher training in the social sciences: an experiment with minecraftedu. International Journal of Educational Technology in Higher Education, 13(1):2.

[Csikszentmihalyi 1997] Csikszentmihalyi, M. (1997). Finding flow: The psychology of engagement with everyday life. Basic Books.

[Dicheva and Dichev 2015] Dicheva, D. and Dichev, C. (2015). Gamification in education: Where are we in 2015? In E-Learn: World Conference on E-Learning in Corporate, Government, Healthcare, and Higher Education, pages 1445-1454. Association for the Advancement of Computing in Education (AACE).

[Hamari and Koivisto 2014] Hamari, J. and Koivisto, J. (2014). Measuring flow in gamification: Dispositional flow scale-2. Computers in Human Behavior, 40:133-143.

[Hamari et al. 2014] Hamari, J., Koivisto, J., and Sarsa, H. (2014). Does gamification work?-a literature review of empirical studies on gamification. In System Sciences (HICSS), 2014 47th Hawaii International Conference on, pages 3025-3034. IEEE.

[Hamari et al. 2016] Hamari, J., Shernoff, D. J., Rowe, E., Coller, B., Asbell-Clarke, J., and Edwards, T. (2016). Challenging games help students learn: An empirical study on engagement, flow and immersion in game-based learning. Computers in Human Behavior, 54:170-179.

[Hanus and Fox 2015] Hanus, M. D. and Fox, J. (2015). Assessing the effects of gamification in the classroom: A longitudinal study on intrinsic motivation, social comparison, satisfaction, effort, and academic performance. Computers \& Education, 80:152-161.

[Likert 1932] Likert, R. (1932). A technique for the measurement of attitudes. Archives of psychology.

[Marczewski 2013] Marczewski, A. (2013). A player type framework for gamification design. URL: https://www. gamified. $u k$.

[Masthoff and Vassileva 2015] Masthoff, J. and Vassileva, J. (2015). Tutorial on personalization for behaviour change. In Proceedings of the 20th International Conference on Intelligent User Interfaces, pages 439-442. ACM. 
VII Congresso Brasileiro de Informática na Educação (CBIE 2018)

Anais dos Workshops do VII Congresso Brasileiro de Informática na Educação (WCBIE 2018)

[Monterrat et al. 2015] Monterrat, B., Desmarais, M., Lavoué, E., and George, S. (2015). A player model for adaptive gamification in learning environments. In International Conference on Artificial Intelligence in Education, pages 297-306. Springer.

[Monterrat et al. 2014a] Monterrat, B., Lavoué, É., and George, S. (2014a). A framework to adapt gamification in learning environments. In European Conference on Technology Enhanced Learning, pages 578-579. Springer.

[Monterrat et al. 2014b] Monterrat, B., Lavoué, E., and George, S. (2014b). Motivation for learning: Adaptive gamification for web-based learning environments. In 6th International Conference on Computer Supported Education (CSEDU 2014), pages 117-125.

[Monterrat et al. 2014c] Monterrat, B., Lavoué, É., and George, S. (2014c). Toward an adaptive gamification system for learning environments. In International Conference on Computer Supported Education, pages 115-129. Springer.

[Nacke et al. 2014] Nacke, L. E., Bateman, C., and Mandryk, R. L. (2014). Brainhex: A neurobiological gamer typology survey. Entertainment computing, 5(1):55-62.

[Nah et al. 2014] Nah, F. F.-H., Zeng, Q., Telaprolu, V. R., Ayyappa, A. P., and Eschenbrenner, B. (2014). Gamification of education: a review of literature. In International conference on hci in business, pages 401-409. Springer.

[Orji 2014] Orji, R. (2014). Design for behaviour change: a model-driven approach for tailoring persuasive technologies. $\mathrm{PhD}$ thesis.

[Orji et al. 2014] Orji, R., Mandryk, R. L., and Vassileva, J. (2014). Selecting effective strategies for tailoring persuasive health games to gamer types.

[Orji et al. 2013] Orji, R., Mandryk, R. L., Vassileva, J., and Gerling, K. M. (2013). Tailoring persuasive health games to gamer type. In Proceedings of the SIGCHI Conference on Human Factors in Computing Systems, pages 2467-2476. ACM.

[Paiva et al. 2015a] Paiva, R., Barbosa, A., Batista, E., Pimentel, D., and Bittencourt, I. I. (2015a). Badges and xp: An observational study about learning. In Frontiers in Education Conference (FIE), 2015 IEEE, pages 1-8. IEEE.

[Paiva et al. 2016] Paiva, R., Bittencourt, I. I., Tenório, T., Jaques, P., and Isotani, S. (2016). What do students do on-line? modeling students' interactions to improve their learning experience. Computers in Human Behavior, 64:769-781.

[Paiva et al. 2015b] Paiva, R. O. A., Bittencourt, I. I., da Silva, A. P., Isotani, S., and Jaques, P. (2015b). Improving pedagogical recommendations by classifying students according to their interactional behavior in a gamified learning environment. In Proceedings of the 30th Annual ACM Symposium on Applied Computing, pages 233-238. ACM.

[Pedro et al. 2015] Pedro, L. Z., Lopes, A. M., Prates, B. G., Vassileva, J., and Isotani, S. (2015). Does gamification work for boys and girls?: An exploratory study with a virtual learning environment. In Proceedings of the 30th Annual ACM Symposium on Applied Computing, pages 214-219. ACM.

[Wohlin et al. 2012] Wohlin, C., Runeson, P., Höst, M., Ohlsson, M. C., Regnell, B., and Wesslén, A. (2012). Experimentation in software engineering. Springer Science \& Business Media. 